Yüzüncü Y1l Üniversitesi
Fen Bilimleri Enstitüsü Dergisi
http://dergipark.gov.tr/yyufbed

Araştırma Makalesi

\title{
Yeşil Nohut Kabuğu Atıklarının Sulu Çözeltiden Pb (II) Biyosorpsiyonunda Değerlendirilmesi
}

\author{
Kübra KORKMAZ ${ }^{* 1}$, Hasan SAYĞILI ${ }^{2}$ \\ ${ }^{1}$ Van Yüzüncü Yıl Üniversitesi, Mühendislik Fakültesi, Gıda Mühendisliği Bölümü, 65080, Van, Türkiye \\ ${ }^{2}$ Batman Üniversitesi, Teknik Bilimler Meslek Yüksek Okulu, Kimya ve Kimyasal İşlemler Teknolojileri \\ Bölümü, 72100, Batman, Türkiye
}

Kübra KORKMAZ, ORCID No: 0000-0001-9338-7205, Hasan SAYĞILI, ORCID No:0000-0003-4900-8268

*Sorumlu yazar e-posta: kubrak0rkmaz@outlook.com

\section{Makale Bilgileri}

Geliş: 01.07.2021

Kabul: 04.11.2021

Online Aralık 2021

DOI: 10.53433/yyufbed.960478

\section{Anahtar Kelimeler}

Yeşil nohut kabuğu,

Biyosorpsiyon,

Kurşun,

İzoterm,

Kinetik
Öz: $\mathrm{Bu}$ çalışmada, toksik bir ağır metal olarak bilinen kurşun $\mathrm{Pb}$ (II) iyonunun, yeni bir alternatif olarak yeşil nohut kabuğu (YNK) kullanılarak sucul ortamdan giderimi araştırılmıştır. Biyosorpsiyon çalışmaları kesikli yönteme göre yürütülmüştür. Optimum $\mathrm{Pb}(\mathrm{II})$ giderimi için gerekli koşullar belirlenerek sıcaklığa bağlı kinetik ve izoterm çalışmaları yapılmıştır. Çalışmalar sonucunda elde edilen kinetik veriler, yalancı birinci, yalancı ikinci ve parçacık içi difüzyon modellerinde değerlendirilerek kinetik model tespiti yapılmıștır. İzoterm verileri ise Langmuir ve Freundlich izoterm modellerinde değerlendirilmiştir. $\mathrm{Pb}(\mathrm{II})$ iyonunun YNK ile biyosorpsiyonunda, optimum koşullar biyosorbent dozu $0,1 \mathrm{~g}$ ve sıcaklık $40{ }^{\circ} \mathrm{C}$ olarak saptanmıştır. Çalışmada, maksimum biyosorpsiyon kapasitesi $\mathrm{Pb}(\mathrm{II})$ iyonu için $30,8 \mathrm{mg} / \mathrm{g}$ olarak bulunmuștur. Ayrıca izoterm verilerinin Langmuir izoterm modeline uygun olduğu $\left(\mathrm{R}^{2}=0,99\right)$ bulunmuş olup, yalancı birinci derece reaksiyon modelinin ise kinetik açıdan en uygun model olduğu $\left(\mathrm{R}^{2}=0,99\right)$ tespit edilmiştir. Çalışma, YNK atığının belli bir biyosorplama kapasitesinin olduğunu ve bu atığın düşük maliyetli çevreci bir alternatif olarak kullanılabileceğini ortaya koymuştur.

\section{Evaluation of Green Chickpea Shell Waste in Pb (II) Biosorption from Aqueous Solution}

\section{Article Info}

Recieved: 01.07.2021

Accepted: 04.11.2021

Online December 2021

DOI: $10.53433 /$ yyufbed. 960478

\section{Keywords}

Green chickpea shell,

Biosorption,

Lead,

İsotherm,

Kinetics

\begin{abstract}
In this study, removal of lead $\mathrm{Pb}(\mathrm{II})$ ion known as a toxic heavy metal from the aqueous media using green chickpea shell (YNK) as a new alternative has been investigated. Biosorption studies were carried out according to the batch method. The necessary conditions for optimum $\mathrm{Pb}(\mathrm{II})$ removal have been determined and temperature dependent kinetic and isotherm studies have been carried out. The kinetic data obtained as a result of the studies have been evaluated in pseudo-first, pseudo-second and intra-particle diffusion models to determine kinetic model. Isotherm data have been evaluated in Langmuir and Freundlich isotherm models. Optimum conditions have been determined for $\mathrm{Pb}$ (II) ion biosorption with YNK as $0.1 \mathrm{~g}$ biosorbent dose and at $40{ }^{\circ} \mathrm{C}$ temperature . In the study, the maximum biosorption capacity has been found to be $30.8 \mathrm{mg} / \mathrm{g}$ for $\mathrm{Pb}(\mathrm{II})$ ion. In addition, the isotherm data have been found to be favorable to Langmuir isotherm model $\left(\mathrm{R}^{2}=0.99\right)$ and the most appropriate kinetic model has been determined to be the pseudo first order reaction model $\left(\mathrm{R}^{2}\right.$ $=0.99$ ). The study showed that YNK waste, has a certain biosorption capacity and this waste can be used as a low-cost and environmentally friendly alternative.
\end{abstract}




\section{Giriş}

Birçok endüstride (gıda endüstrisi, tekstil endüstrisi vb.) hammaddelerin işlenmesi sırasında atıklar oluşmaktadır. Oluşan atıkların giderilmesi hem ciddi çevre sorunlarına hem de işletmeler için maddi kayıplara neden olmaktadır. Bu nedenle atıkların yönetimi ve değerlendirilmesi yönünde yapılan çalışmalar günümüzde hız kazanmıştır (Şener, 2008; Yağc1, 2006).

Alıcı ortama boşaltılan atıkların kimyasal ve fiziksel nitelikleri kirliliğin türüne dair bir fikir verse de boyutu açısından öngörülebilir sonuçlar doğurmayabilir. Dolayısıyla atık suların, kaynaklandığı işletmedeki sistemlerde kontrol edilmesi ve sürdürülebilir atık su yönetiminin sağlanması gerekmektedir.

Atık sularda sıklıkla rastlanan ağır metaller ciddi kirlilik unsuru olmaya devam etmektedir. Yaygın bir örnek olarak kurşun ise hava, su, toprak, solunum ve besinler yoluyla biyolojik sistemlere giren zehirleyici özelliklere sahip ağır bir metaldir. Birçok ortamda istenmeyen konsantrasyonlarda kurşun kirliliğine rastlanmaktadır. Akü ve pil fabrikaları, kurşun maden ve metal endüstrileri, petrol rafinerileri, patlayıcı sanayi atık suları bunlardan sadece birkaçına örnek olarak verilebilir.

İnorganik kurşun bileşikleri solunum ve sindirim gibi yollarla insan vücuduna girer. Kan dolaşımına giren kurşunun insan sağlığı üzerine pek çok zararı olduğu bilinmekle beraber anemi, yüksek tansiyon, gelişim çağındaki çocuklarda zihinsel fonksiyon bozuklukları, immünolojik bozukluklar, böbrek fonksiyon bozuklukları ve üreme fonksiyon bozuklukları en dikkat çekici olanlarıdır (Jaishankar ve ark., 2014).

Atık sulardan ağır metal gideriminde kimyasal çöktürme ve filtrasyon, kimyasal oksidasyon ve indirgeme, iyon değişim filtrasyonu, elektrokimyasal prosesler, ters osmoz, membran teknolojileri ve buharlaştırma, adsorpsiyon gibi geleneksel yöntemler yer almaktadır ve bu yöntemlerin bazı avantaj ve dezavantajları çizelge 1'de verilmiştir (Ahluwalia ve Goyal, 2007; Hanif ve ark., 2007).

Çizelge 1. Atık sulardan geleneksel metal giderme yöntemlerinin avantaj ve dezavantajları

\begin{tabular}{|c|c|c|}
\hline Metot & Avantaj & Dezavantaj \\
\hline $\begin{array}{l}\text { Kimyasal çöktürme ve } \\
\text { filtrasyon }\end{array}$ & $\begin{array}{l}\text { Basit ve ucuz bir teknik } \\
\text { olmas1 }\end{array}$ & $\begin{array}{l}\text { Yüksek konsantrasyonlarda güçlükle } \\
\text { ayrılma, atık çamur oluşumu }\end{array}$ \\
\hline $\begin{array}{l}\text { Kimyasal oksidasyon ve } \\
\text { indirgeme }\end{array}$ & İnaktivasyon & Ortam hassasiyeti \\
\hline İyon değişim filtrasyonu & $\begin{array}{l}\text { Etkili arıtım ve atık } \\
\text { metalin geri kazanımı }\end{array}$ & $\begin{array}{l}\text { Kullanılan reçinelerin kontaminasyon } \\
\text { hassasiyeti, pH duyarlılığ } 1 \text { ve maliyet }\end{array}$ \\
\hline $\begin{array}{l}\text { Elektrokimyasal } \\
\text { prosesler }\end{array}$ & $\begin{array}{l}\text { Atık metalin geri kazanımı } \\
\text { ve geri dönüşüm }\end{array}$ & $\begin{array}{l}\text { Etkinliğinin yüksek konsantrasyonlarda } \\
\text { olması ve maliyet }\end{array}$ \\
\hline Ters osmoz & $\begin{array}{l}\text { Atık metalin geri kazanımı } \\
\text { ve geri dönüşüm }\end{array}$ & Yüksek basınç, maliyet \\
\hline Buharlaştırma & $\begin{array}{l}\text { Attk metalin geri } \\
\text { dönüsümü }\end{array}$ & $\begin{array}{l}\text { Yüksek enerji ihtiyacı, maliyet ve atık } \\
\text { camur olusumu }\end{array}$ \\
\hline Adsorpsiyon & Etkili arıtım, ekonomik & $\begin{array}{l}\text { Performans arttırmak için fazla miktarda } \\
\text { aktif karbon kullanma gerekliliği }\end{array}$ \\
\hline
\end{tabular}

Çizelge 1'de görüldüğü gibi bu tekniklerin kıyaslandığında bazı avantaj ve dezavantajları olmakla beraber son yıllarda ağır metal iyonlarının sulu çözeltiden adsorpsiyon metoduyla uzaklaştırılmasında tarımsal atıkların kullanımı yönündeki çalışmalar artmıştır. Biyosorpsiyon olarak adlandırılan bu yöntemin geleneksel arıtma prosesleri ile kıyaslandığında temini kolay ve uygun maliyetli olan biyokütlelerin kullanımına olanak sağlaması, yüksek verim, kimyasal madde gereksiniminin az olması, metallerin geri kazanım olasıllı̆ı ile günümüzde ilgi gören bir arıtma prosesi haline gelmiştir. 
Biyosorpsiyon, sulu ortamdan toksik metal iyonlarının uzaklaştırılmasında biyolojik kökenli kütlelerin kullanıldığı bir süreçtir ve biyosorplanan maddenin kullanılan biyokütle hücreleri yüzeyine taşınması ve buraya tutunması esasına dayanır. Süreçte iyonik güç, $\mathrm{pH}$, sıcaklık, metal iyonlarının kimyasal özellikleri, metal iyon konsantrasyonu, temas süresi, biyosorbentin hücre bileşim ve özellikleri gibi pek çok faktör rol oynamaktadır.

Esas olarak polisakkaritler, proteinler ve lipitlerden meydana gelen bu biyosorbent hücrelerinin metal iyonlarını bağlayıcı özelliği hücre duvarlarındaki karboksil, hidroksil, fosfat ve amino asit gibi fonksiyonel gruplardan kaynaklanmaktadır (Göksungur ve ark., 2005).

Literatürde findık kabuğu (Demirbas, 2003), Hindistan cevizi (Kavitha \& Namasivayam, 2007), portakal kabuğu (Chen \& Chen, 2009), limon kabuğu (Demirbas ve ark., 2004), elma posas1, buğday samanı, mısır koçanı ve arpa kabuğu (Robinson ve ark., 2002), yengeç kabuğu (Vijayaraghavan ve ark., 2006), şeker pancarı posası (Reddad ve ark., 2002), karpuz kabuğu (Bhattacharjee ve ark., 2020) ve daha pek çok atık biyosorpsiyon metodu ile çeşitli kirlilik etmenlerini gidermede değerlendirilmiştir.

$\mathrm{Bu}$ araştırmada biyosorpsiyon çalışmalarına katkı sağlamak amacıyla, atık sudan kurşun arıtımında doğal bir biyosorbent olarak daha önce çalışılmamış yeşil nohut kabuğu atıklarının kullanılabilme potansiyeli incelenmiştir. Biyosorpsiyon sürecini etkileyen doz, sıcaklık, derişim gibi parametreler incelenerek optimum değerler belirlenmiştir. Ayrıca kinetik ve izoterm verileri de değerlendirilmiş olup modellemeler yapılmıştır.

\section{Materyal ve Yöntem}

\subsection{Biyosorbent ve kimyasal maddeler}

Çalışmada biyosorbent olarak yeşil nohut kabuğu atıkları (YNK) kullanılmıştır. Batman ilinden evsel ölçekte toplanan biyokütlelerden toz, kirlilik, renk bileşenleri tamamen uzaklaşana kadar saf su ile yıkanmış, daha sonra kurutulan numune bitki öğütücü (IKA 20) ile öğütülmüş ve elenmiştir. $1000 \mu \mathrm{m}(18 \mathrm{mesh})$ elek üstü boyutundaki kısım toplanıp cam şişelerde stoklanarak biyosorbent kullanıma hazır hale getirilmiştir. \%99,5 saflık derecesindeki kurşun (II) nitrat $\left(\mathrm{Pb}\left(\mathrm{NO}_{3}\right)_{2}\right)$ ise Merck firmasından temin edilmiştir. Bir Pb(II) çözeltisi hazırlanmış ve çalışmalardan önce bu çözeltiden istenen seyreltik çözeltiler oluşturulmak için kullanılmıştır.

\subsection{Biyosorbent karakterizasyonu}

Biyosorbent karakterizasyonu için nem, kül, uçucu madde, sabit karbon tayinleri yapılarak kimyasal özellikleri belirlenmiştir. Yüzey fonksiyonel gruplarını belirlemek ve biyosorpsiyondan sonra yüzeyde tutulum mekanizmasını anlamak amacıyla FTIR spektrumları (Perkin Elmer Spectrum 100) alınmıştır. Ayrıca, morfolojik yapılarını incelemek için taramalı elektron mikroskobu (SEMZEISS-Supra 40 VP) analizi de yapılmıştır.

\subsection{Deneysel çalışmalar}

\subsubsection{Biyosorbent doz etkisi}

$\mathrm{Pb}$ (II) biyosorpsiyonuna en uygun doz etkisini belirlemek için seçilen beş noktalı aralık olarak biyosorbentten 0,1-0,5 g arasında tartımlar alınarak $50 \mathrm{~mL}$ 'lik erlenlere konulmuştur. Biyosorbentlerin üzerine $100 \mathrm{ppm}$ konsantrasyonundaki $\mathrm{Pb}$ (II) çözeltisinden $50 \mathrm{~mL}$ eklenerek $120 \mathrm{rpm}$ hızındaki çalkalayıcılı su banyosuna (Wisebath-WIS 30) konulmuş ve 1 saat sonunda çözeltilerden örnekler filtre edilerek alınmıştır. Alevli Atomik Spektrofotometre (AAS -Perkin Elmer AAanalyst 400) ile yapılan analizlerde elde edilen $\mathrm{C}_{\mathrm{o}}$ ve $\mathrm{C}_{\mathrm{e}}$ değerleri, Denklem 1 de $\mathrm{q}(\mathrm{mg} / \mathrm{g})$ değerleri hesaplanarak maksimum uzaklaştırılmanın gerçekleştiği doz miktarı belirlenmiştir.

$$
q=\frac{C_{0}-C_{e}}{m} \cdot V
$$


Eşitlikteki $q, C_{e}, V$ ve $m$ sırasıyla birim biyosorbent üzerine biyosorplanan madde miktarı $(\mathrm{mg} / \mathrm{g})$, denge anındaki $\mathrm{Pb}(\mathrm{II})$ derişimini $(\mathrm{mg} / \mathrm{L})$, çözelti hacmi (L) ve kullanılan biyosorbent kütlesidir (g).

\subsubsection{Başlangıç derişimi ve denge temas süresi etkisi}

YNK'nın sulu çözeltiden $\mathrm{Pb}(\mathrm{II})$ iyonu gideriminde başlangıç derişimi ve denge temas süresi etkilerini incelemek için, doğal $\mathrm{pH}(5,85)$ ve belirlenen optimum doz olan $0,1 \mathrm{~g}$ YNK ile $\mathrm{C}_{\mathrm{o}}$ 'ları 100$300 \mathrm{ppm}$ aralığında olan çözeltilerden $50 \mathrm{~mL}$ alınarak $25^{\circ} \mathrm{C}$ 'de ve $120 \mathrm{rpm}$ çalkalama hızında zamana bağlı (5-420 dk) olarak çalışılmıştır. AAS ile yapılan analizden elde edilen $\mathrm{C}_{0}$ ve $\mathrm{C}_{\mathrm{e}}$ değerleri Denklem 1 de değerlendirilerek q değerleri hesaplanmış ve daha sonra tüm derişimler için elde edilen $\mathrm{q}$ değerlerine karşı $t$ değerleri grafiğe geçirilmiştir.

\subsubsection{Kinetik çalışmalar}

Sulu çözeltiden YNK biyosorplayıcısı ile Pb(II) giderimindeki çalışmalarda elde edilen veriler kinetik modelleme yapmak için yalancı birinci dereceden (Denklem 2), yalancı ikinci dereceden (Denklem 3) ve partikül içi difüzyon modelleri (Denklem 4) kinetik denklemlerinde değerlendirilerek kinetik paramatreler, $\mathrm{R}^{2}$ ler ve difüzyon hız sabitleri belirlenmiştir (Lagergren, 1898; Ho \& Mckey, 1999; Weber \& Morris, 1963).

$$
\begin{gathered}
\ln \left(q_{e}-q_{t}\right)=\ln q_{e}-k_{a d s} t \\
\frac{t}{q_{t}}=\frac{1}{k_{a d s 2} q_{e}^{2}}+\frac{1}{q_{e}} t \\
q t=k i \cdot t^{1 / 2}+C
\end{gathered}
$$

Buradaki $k_{a d s}, k i, t$ ve $C$ sırasıyla hız sabiti $\left(\mathrm{dk}^{-1}\right)$, partikül içi difüzyon hız sabiti (dak ${ }^{-2}$ ), temas süresi ve biyosorplanan ile biyosorbent arasında oluşan tabakanın kalınlığı ile ilgili bilgi veren parametredir ve qt'nin $\mathrm{t}^{1 / 2}$, ye karşı oluşturulan grafiğin eğimi hız sabitini verirken, kesim noktası ise C' yi verir.

\subsection{4. İzoterm çalışmaları}

$\mathrm{Pb}$ (II) iyonu biyosorpsiyonu izoterm çalışmalarında farklı derişim $\left(\mathrm{C}_{0}\right)$ ve sıcaklıklarda $(20,25$ ve $30{ }^{\circ} \mathrm{C}$ ) elde edilen $\mathrm{q}_{\mathrm{e}}$ değerleri $\mathrm{C}_{\mathrm{e}}$ 'ye karş1 grafiğe geçirilerek izoterm eğrileri oluşturulmuştur. İzoterm modellemesi yapmak üzere Langmuir (Denklem 5) ve Freundlich (Denklem 6) izoterm denklemleri kullanılmıştır (Langmuir, 1918; Freundlich ,1906).

$$
\begin{gathered}
\frac{C_{e}}{q_{e}}=\frac{1}{q_{m} \cdot b}+\frac{C_{e}}{q_{m}} \\
q_{e}=K_{f} C_{e} e^{1 / n}
\end{gathered}
$$

Burada, $q_{m}$ ve $b$ sirasiyla biyosorbentin tek tabaka tutma kapasitesi $(\mathrm{mg} / \mathrm{g})$ ve adsorpsiyon enerjisi $(\mathrm{L} / \mathrm{mg})$ ile ilgili olan bir sabittir. $K_{f}$ ve $n$ ise sırasıyla freundlich adsorpsiyon kapasitesi ve şiddetini gösteren sabittir.

Ayrıca Hall ayırma faktörü $R_{L}, \mathrm{~Pb}(\mathrm{II})$ başlangıç konsantrasyonu ile ilgili olan ve biyosorpsiyon prosesinin davranışını gösteren boyutsuz bir sabittir. Langmuir izoterminin temel özellikleri bu faktör sayesinde tanımlanabilir. 


$$
R_{L}=\frac{1}{1+b C_{0}}
$$

$R_{L}$ değeri izoterm tipini tanımlar. İzoterm tipleri $R_{L}$ değeri 0 ve 1 arasındaysa $\left(0<R_{L}<1\right)$ uygun, 1'den büyükse $\left(R_{L}>1\right)$ uygun olmayan, 1'e eşitse $\left(R_{L}=1\right)$ lineer ve 0 'a eşitse $\left(R_{L}=0\right)$ tersinmez olmak üzere 4'e ayrilır (Hall ve ark., 1966).

\section{Bulgular ve Tartışma}

\subsection{Biyosorbent karakterizasyonu}

Yeşil nohut kabuklarının karakterizasyonu amacıyla yapılan nem, kül, uçucu madde ve sabit karbon analizleri Çizelge 2' de verilmiştir.

Çizelge 2. YNK'nın karakterizasyon analiz sonuçları (\%)

\begin{tabular}{ll}
\hline Analizler & $\%$ Miktar \\
\hline Nem miktarı & 8,02 \\
Kül miktarı & 17,79 \\
Uçucu madde & 78,89 \\
Sabit karbon & 3,32 \\
\hline
\end{tabular}

Biyosorbent hücrelerindeki karboksil, hidroksil, fosfat ve amino asit gibi fonksiyonel grupları aydınlatmak için alınan biyosorpsiyon öncesi ve sonrası FTIR spektrumu Şekil 1'de verilmiştir. Biyosorpsiyon öncesi görülen 3285,21 $\mathrm{cm}^{-1}$ pik, yüzeydeki $-\mathrm{OH}$ gruplarının var olduğunu

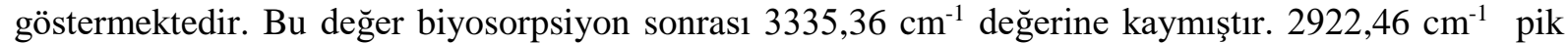
yüzeydeki alifatik metil $\left(-\mathrm{CH}_{3}\right)$ ve metilen $\left(-\mathrm{CH}_{2}\right)$ fonksiyonel gruplarına ait asimetrik ve simetrik $-\mathrm{C}$ $\mathrm{H}$ gerilmesinin olduğunu göstermektedir. Bu değer ise biyosorpsiyondan sonra $2911,64 \mathrm{~cm}^{-1}$ değerlerine kaymıştır. $1624,20 \mathrm{~cm}^{-1}$ deki pik $\mathrm{C}=\mathrm{N}$ - esneme titreşimleri ve amino gruplarının var olduğunu göstermektedir. Bu değer, biyosorpsiyondan sonra 1625,64 değerine kaymıştır. 1402,86 ve $1240,03 \mathrm{~cm}^{-1}$ deki bant O-H eğilme ve C-O esneme titreşimlerinden kaynaklanabilmektedir.1402,86 deki pik biyosorpsiyondan sonra kaybolmuştur. $1240,03 \mathrm{~cm}^{-1}$ deki pik alkol ve fenol gruplarının var olduğunu ve O-H esneme titreşimlerini göstermekte ve bu değer 1238,98 değerlerine kaymıştır. $1013,49 \mathrm{~cm}^{-1}$ deki pik halojenli bileşiklerdeki $\mathrm{C}$ esneme hareketlerini göstermektedir. Biyosorpsiyondan sonra FTIR spektrumlarında meydana gelen artma ve azalmalar bu aktif grupların biyosorpsiyona katıldığının göstergesi olarak değerlendirilmiştir (Yargıç ve ark., 2015).

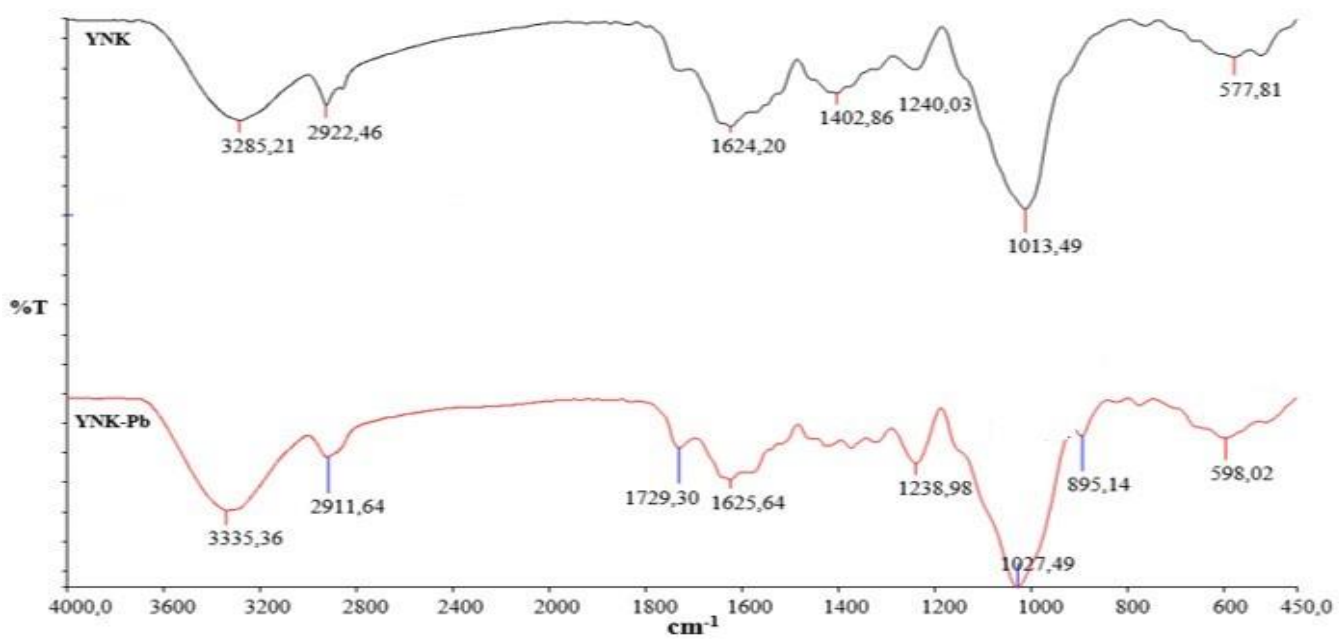

Şekil 1. YNK'nın Pb(II) biyosorpsiyonu öncesi ve sonrası FTIR spektrumları 


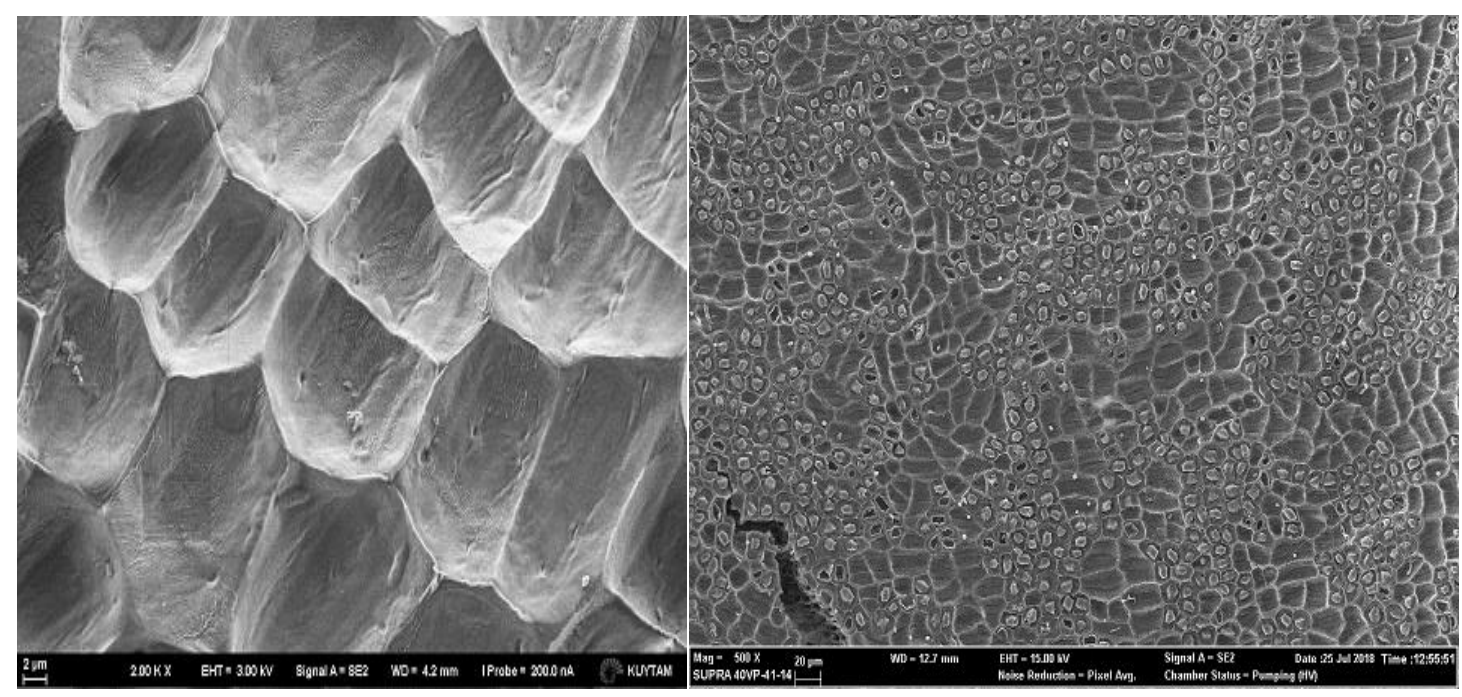

(a) (b)

Şekil 2. YNK'nın Pb(II) biyosorpsiyonu öncesi (a) ve sonrası (b) SEM görüntüleri

Yüzey morfolojisini aydınlatmak için biyosorpsiyondan önce ve sonra biyosorbentin SEM görüntüleri alınmıştır. Elde edilen sonuçlara göre YNK biyosorbentinin makrogözenekleri çoğunlukludur. Şekil (b) görüldüğü gibi biyosorpsiyondan önce daha pürüzlü olan yüzey, biyosorpsiyondan sonra yüzeye metal iyonlarının bağlanmasıyla daha homojen bir hale gelmiştir. Bu da $\mathrm{Pb}(\mathrm{II})$ 'nin aktif bölgelere tutularak yapıyı değiştirdiğini göstermektedir.

\subsection{Biyosorbent dozunun etkisi}

Biyosorbent dozu, bu teknikle arıtım sürecinde önemli bir etkiye sahiptir. Biyosorbent dozunun bilinmesi giderilen kirleticinin konsantrasyonu için gerekli olan biyosorbent kapasitesinin belirlenmesinde önemli bir etken olacaktır. Bu çalışmada, seçilen aralıktaki doz miktarı 0,1 g'dan 0,5 g'a arttıkça dengede biyosorplanan $\mathrm{Pb}$ (II) konsantrasyonlarının $6,49 \mathrm{mg} / \mathrm{g}$ 'dan 1,78 mg/g'a düştüğü ve buna bağlı olarak biyosorpsiyon kapasitesinin azaldığı görülmektedir (Şekil 3). Bu durum biyosorbent dozunun artması ile biyosorplanan miktarın biyosorplayıcı yüzeyini tümüyle kaplamada yetersiz olabileceğinden kaynaklandığ 1 düşünülmektedir. Başka bir deyiş ile biyosorbent miktarındaki artış ile biyosorbent parçacıklarının birbirine teması, birikmesi, topaklanması daha fazla olabilir ve biyosorplanan maddelerin biyosorbent ile temas eden yüzey alanını azaltan bu durumdan dolayı biyosorpsiyon kapasitesini azaltmış olabilir (Kavc1, 2021).

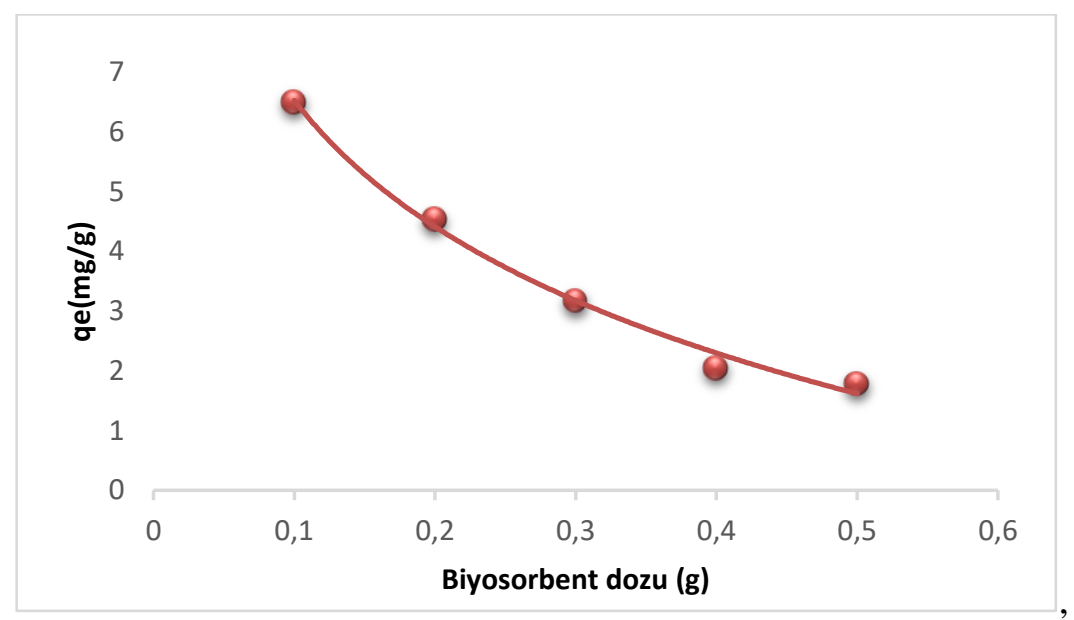

Şekil 3. $\mathrm{Pb}$ (II) gideriminde biyosorbent miktarının etkisi (Sıcaklık $25^{\circ} \mathrm{C}$, karıştırma hızı $120 \mathrm{rpm}$,

$$
\mathrm{C}_{0}=100 \mathrm{ppm}, \mathrm{t}=1 \text { saat, } \mathrm{pH}=5,85 \text { ) }
$$




\subsection{Başlangıç $\mathrm{Pb}(\mathrm{II})$ iyonu konsantrasyonu ve denge temas süresinin biyosorpsiyona etkilerinin değerlendirilmesi}

Atıksu arıtma proseslerinde başlangıç kirletici konsantrasyonlarındaki değişim prosesin başarılı bir şekilde gerçekleştirilebilmesi için büyük önem taşımaktadır. Atık sudaki $\mathrm{Pb}$ (II) konsantrasyonlarında meydana gelebilecek farklılıklarda sistemin ne şekilde tepki vereceği iyi bilinmelidir.

Başlangıç $\mathrm{Pb}$ (II) iyonu konsantrasyonunun biyosorpsiyona etkisi incelenirken $0,1 \mathrm{~g}$ biyosorbent kullanılarak $\mathrm{Pb}(\mathrm{II})$ iyonu konsantrasyonu sirasiyla 100,200 ve 300 ppm olarak değiştirilmiştir. Başlangıç $\mathrm{Pb}$ (II) iyonu konsantrasyonunun 100 ppm'den 300 ppm'e yükseldikçe biyosorpsiyon kapasitesinin de arttığı gözlemlenmektedir (Şekil 4). Bunun nedeni, başlangıç metal konsantrasyonu arttıkça itici güç arttığından, biyosorpsiyon genellikle artar. Artış, yüzeyin doygunluk konsantrasyonuna ulaşmasıyla son bulur (Turan, 2012). Benzer şekilde Öztürk ve ark. (2020) yaptıkları çalı̧̧mada çay atıkları ile Ni (II) ağır metal gideriminde başlangıç metal konsantrasyonuyla biyosorpsiyon kapasitesinin arttığını belirttikleri gibi pek çok çalışma bunu desteklemektedir.

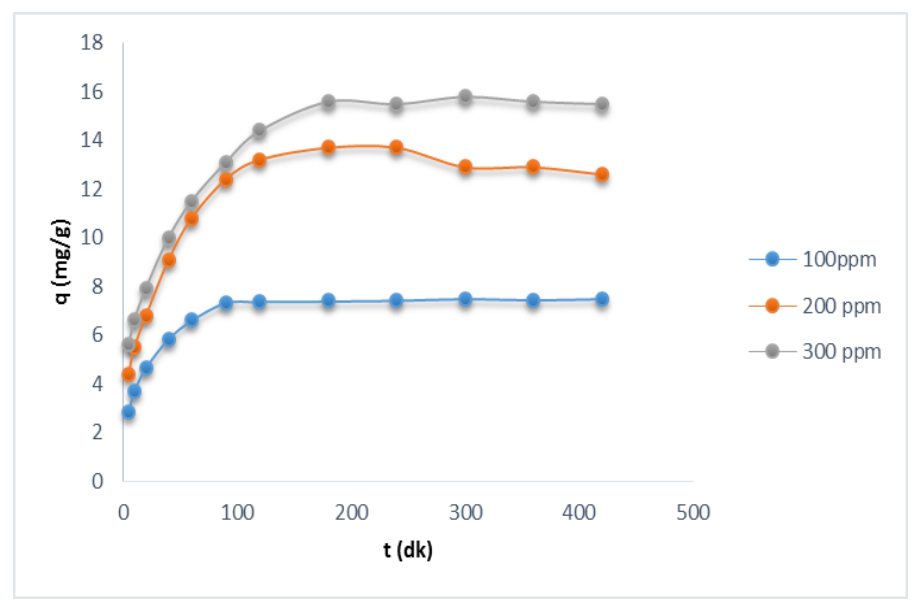

Şekil 4. $\mathrm{Pb}$ (II) Başlangıç konsantrasyonunun etkisi (Sıcaklık $25^{\circ} \mathrm{C}$, karıştırma hızı $120 \mathrm{rpm}, \mathrm{m}=0,1$ $\mathrm{g}, \mathrm{pH}=5,85)$

Çalışmada $\mathrm{Pb}(\mathrm{II})$ biyosorplamada denge temas süresinin artması ile biyosorpsiyon kapasitesinin de arttığı ve bu durumun dengeye gelene kadar devam ettiği gözlemlenmiştir. Bu artış durumu 180. dakikalara kadar devam etmiştir. Denge süresi biyosorbentin doygunluğa ulaştığı nokta olarak belirlenmiştir.

\subsection{Sıcaklığın biyosorpsiyon üzerinde etkisi}

Sicaklık biyosorpsiyon prosesini etkileyen önemli bir faktördür. Sicaklığın YNK tarafından $\mathrm{Pb}$ (II) giderimi üzerine etkisini incelemek için $20^{\circ} \mathrm{C}, 30^{\circ} \mathrm{C}$ ve $40{ }^{\circ} \mathrm{C}$ çalışma sicaklıkları olarak seçilmiştir. Seçilen bu aralıkta sıcaklı̆̆ın $20{ }^{\circ} \mathrm{C}$ 'den $40{ }^{\circ} \mathrm{C}$ 'ye artması ile biyosorpsiyon kapasitesinin de $18,8 \mathrm{mg} / \mathrm{g}$ 'dan $30,8 \mathrm{mg} / \mathrm{g}$ 'a arttığ 1 dolayısıyla biyosorpsiyon kapasitesinin sıcaklığa bağlı artış gösterdiği belirlenmiştir (Şekil 5). Bu durumun genellikle sıcaklıktaki artışın metal iyonlarının hareketliliği arttırdığından kaynaklandığı düşünülmektedir (Wan ve ark., 2014). Yine artan sıcaklıkla birlikte biyosorbent üzerindeki bağlanma bölgelerinin sayısının arttığı ve daha fazla bölgenin aktif hale geldiği düşünülmektedir (Cruz ve ark., 2003). Dolayısıyla bu durum biyosorbentin iç yüzeyine daha fazla metal iyonlarının difüzyonunu sağlayacaktır. 


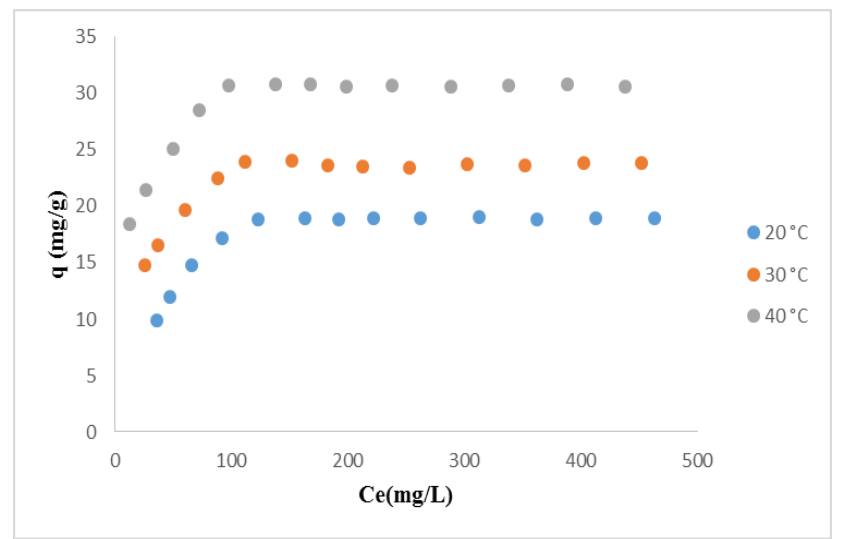

Şekil 5.YNK'nın $\mathrm{Pb}(\mathrm{II})$ biyosorpsiyonunda farklı sicaklıkların biyosorsiyon kapasitesine etkisi (Karıştırma hızı $120 \mathrm{rpm}, \mathrm{t}=24$ saat, $\mathrm{m}=0,1 \mathrm{~g}, \mathrm{pH}=5,85$ )

\subsection{Biyosorpsiyon kinetikleri}

Biyosorpsiyon proseslerinde, kinetik çalışmalar biyosorbentlerin performansları ve mekanizmalarını anlamak için gereklidir. Aynı zamanda biyosorpsiyon hızı tespit edilerek süreci başarıyla gerçekleştirmek için gerekli olan atık suyun alıkonma süresi belirlenmiş olur (Taşar ve ark., 2014; Gupta ve ark., 2010).

Biyosorpsiyon kinetiğini belirlemek amaciyla çalışmada 100-300 ppm olarak seçilen derişimler için yalancı birinci dereceden, yalancı ikinci dereceden ve partikül içi difüzyon kinetik modeller uygulanmıştır (Çizelge 3).

Çizelge 3. Farklı çözelti derişimlerinde YNK'nın Pb(II) biyosorpsiyonu için kinetik parametreler

\begin{tabular}{|c|c|c|c|c|}
\hline \multicolumn{5}{|c|}{ Yalancı birinci dereceden kinetik model } \\
\hline $\mathrm{C}_{\mathrm{o}}(\mathrm{ppm})$ & $\mathrm{q}_{\mathrm{e}, \text { deney }}\left(\mathrm{mg} \mathrm{g}^{-1}\right)$ & $\mathrm{q}_{\mathrm{e}, \text { hesap }}\left(\mathrm{mg} \mathrm{g}^{-1}\right)$ & $\mathrm{k}_{1} \times 10^{-2}\left(\mathrm{~min}^{-1}\right)$ & $\mathrm{R}^{2}$ \\
\hline 100 & 7,32 & 5,04 & 0,031 & 0,9978 \\
\hline 200 & 13,05 & 9,86 & 0,0241 & 0,9963 \\
\hline 300 & 15,06 & 11,1 & 0,0177 & 0,9922 \\
\hline \multicolumn{5}{|c|}{ Yalancı ikinci dereceden kinetik model } \\
\hline $\mathrm{C}_{\mathrm{o}}(\mathrm{ppm})$ & $\mathrm{q}_{\mathrm{e}, \text { deney }}\left(\mathrm{mg} \mathrm{g}^{-1}\right)$ & $\mathrm{q}_{\mathrm{e}, \text { hesap }}\left(\mathrm{mg} \mathrm{g}^{-1}\right)$ & $\mathrm{k}_{1} \times 10^{-2}\left(\mathrm{~min}^{-1}\right)$ & $\mathrm{R}^{2}$ \\
\hline 100 & 7,32 & 8,15 & 0,095 & 0,9968 \\
\hline 200 & 13,05 & 14,9 & 0,034 & 0,9868 \\
\hline 300 & 15,06 & 15,7 & 0,038 & 0,9844 \\
\hline \multicolumn{5}{|c|}{ Partikül içi difüzyon modeli } \\
\hline $\mathrm{C}_{\mathrm{o}}(\mathrm{ppm})$ & $\mathrm{q}_{\mathrm{e}, \text { deney }}\left(\mathrm{mg} \mathrm{g}^{-1}\right)$ & $\mathrm{k}_{\mathrm{id}}\left(\mathrm{mg} \mathrm{g}^{-1} \mathrm{~min}^{-1 / 2}\right)$ & $\mathrm{C}\left(\mathrm{mg} \mathrm{g}^{-1}\right)$ & $\mathrm{R}^{2}$ \\
\hline 100 & 7,32 & 0,2231 & 3,8813 & 0,7045 \\
\hline 200 & 13,05 & 0,451 & 5,5769 & 0,7071 \\
\hline 300 & 15,06 & 0,5638 & 6,1463 & 0,8525 \\
\hline
\end{tabular}

Çizelge 3'te verilen sonuçlara göre YNK ile ile $\mathrm{Pb}(\mathrm{II})$ giderimi kinetiğinde biyosorbentin bu modelden hesaplanmış denge alım kapasitesi qe(hesap) ve deneysel olarak bulunan değer qe(deney) ile yakınlığ 1 ve korelasyon katsayıları büyüklügünden de görüldüğü gibi yalancı birinci derece kinetik modeline daha iyi uyum sağlamıştır. Deneysel verilerin yalancı birinci derece kinetik modeline uygunluğu, biyosorpsiyon kapasitesinin biyosorbentin yüzeyindeki aktif bölgelerle orantılı olduğunu 
göstermektedir. Bu model biyosorpsiyon sürecinde katı kapasitesine dayanan sivi/kat1 sisteminin adsopsiyonu esasına dayanır (Lagergren, 1898).

\subsection{Biyosorpsiyon izotermleri}

Kesikli biyosorpsiyon proseslerinde kullanılan biyokütlelerin maksimum giderim kapasitesini belirlemek için izoterm çalışmaları oldukça önemlidir. Çalışmada 50-500 ppm olmak üzere 13 noktalı derişim ve $20,30,40{ }^{\circ} \mathrm{C}$ olmak üzere üç sıcaklık noktası seçilmiş̧ir. Farklı derişim ve sıcaklık parametreleri 1şı̆̆ında, İzoterm modellerinden elde edilen bulguları değerlendirmek amaciyla Langmuir ve Freundlich modelleri kullanılmıştır (Çizelge 4).

Çizelge 4. Farklı sıcaklıklarda YNK'nın Pb(II) biyosorpsiyonu için izoterm parametreleri

\begin{tabular}{|c|c|c|c|c|c|}
\hline \multicolumn{6}{|c|}{ Langmuir izotermi } \\
\hline Sicaklık $\left({ }^{\circ} \mathrm{C}\right)$ & $\mathrm{q}_{\mathrm{m}}\left(\mathrm{mg} \mathrm{g}^{-1}\right)$ & $\mathrm{b}\left(\mathrm{L} \mathrm{mg}^{-1}\right)$ & $\mathrm{K}_{\mathrm{L}}$ & $\mathrm{R}_{\mathrm{L}}$ & $\mathrm{R}^{2}$ \\
\hline 20 & 20,08 & 0,0493 & 0,9899 & 0,039 & 0,9962 \\
\hline 30 & 24,51 & 0,0941 & 2,3064 & 0,021 & 0,9989 \\
\hline 40 & 31,45 & 0,1372 & 4,3149 & 0,014 & 0,9994 \\
\hline \multicolumn{6}{|c|}{ Freundlich izotermi } \\
\hline Sicaklık $\left({ }^{\circ} \mathrm{C}\right)$ & $\mathrm{n}\left(\mathrm{L} \mathrm{mg}^{-1}\right)$ & $\mathrm{K}_{\mathrm{F}}$ & $\mathrm{R}^{2}$ & & \\
\hline 20 & 4,6339 & 5,6508 & 0,733 & & \\
\hline 30 & 6,6845 & 10,3636 & 0,7628 & & \\
\hline 40 & 7,1225 & 14,2235 & 0,814 & & \\
\hline
\end{tabular}

Çizelge 4'deki korelasyon katsayıları incelendiğinde YNK ile $\mathrm{Pb}(\mathrm{II})$ biyosorpsiyonunun, Langmuir izotermine Freundlich izoterminden daha iyi uyum sağladığı görülmektedir. Genel olarak Langmuir modeli kirleticilerin adsorbent yüzeyinde belli miktardaki aktif merkeze tek katmanlı adsorpsiyonunu kabul gören ve bu kirleticilerin belli konsantrasyonlarında yüzeyin doygunluğa ulaştığını varsayan teorik bir modeldir (Weber, 1972).

Maksimum biyosorpsiyon kapasitesi olan $\mathrm{q}_{\mathrm{m}}$ ve Langmuir sabiti olan $\mathrm{b}$, sirasiyla 31,45 mg/g ve $0,13720 \mathrm{~L} / \mathrm{mg}$ olarak bulunmuştur. Langmuir izoterm sabiti b, başlangıç $\mathrm{Pb}$ (II) konsantrasyonlarıyla değişim gösteren ayırma faktörünü belirlemek için de kullanılmıştır. Ayırma faktörü $\left(\mathrm{R}_{\mathrm{L}}\right)$, artan başlangıç konsantrasyonları ile azalma göstermiş̧tir. Elde edilen 0,039-0,0140 aralığındaki ayırma faktörü değerlerinin 0-1 aralığında yer alması biyosorpsiyon prosesinin yine bu modele uygun gerçekleştiğini göstermektedir.

Literatürde yapılan bazı çalışmalarda çeşitli biyosorbentler ile kurşun gideriminde bulunan maksimum q değerleri çizelge 5'te verilmiştir.

Çizelge 5. Litaretürde farklı biyosorbentlerin $\mathrm{Pb}(\mathrm{II})$ tutma kapasiteleri

\begin{tabular}{lll}
\hline Kullanılan biyosorbent & $\mathrm{q}(\mathrm{mg} / \mathrm{g})$ & Referans \\
\hline Kolza tohumu & 21.29 & Morosanu ve ark., 2017 \\
Salatalık kabuğu & 133.6 & Basu ve ark., 2017 \\
Çam kabuğu & 76.8 & Gundogdu ve ark., 2009 \\
Kapyabiber çekirdeği & 29.67 & Günȩ, 2018 \\
Modifiye şeker pancarı küspesi & 309.7 & Arslanoğlu \& Tümen, 2015 \\
Karpuz kabuğu & 98.1 & Kelly-Vargas ve ark., 2012 \\
Yeşil nohut kabuğu & 30.8 & Bu çalışma \\
\hline
\end{tabular}


Çizelgede $\mathrm{Pb}(\mathrm{II})$ gideriminde farklı biyosorbentlerin farklı giderim kapasiteleri olduğu görülmektedir. Bu çalışma ve litaratürdeki daha pek çok çalışma örneği ile kıyaslandığında kullanılan YNK biyosorbentinin, bazı çalışmalardan düşük bazı çalışmalardan yüksek bir giderim potansiyeli olduğu görülür. Bunun yanı sıra, modifiye etme gibi daha farklı işlemler ve üzerine yapılabilecek yeni çalışmalar ile bu potansiyel daha da geliştirilebilir.

\section{Sonuç}

$\mathrm{Bu}$ çalışmada, biyosorbent materyali olarak yeşil nohut kabuk atıkları kullanılarak kesikli yöntem ile atık sulardan $\mathrm{Pb}$ (II) giderimi araştırılmıştır. Yapılan çalışmalarda, $\mathrm{Pb}$ (II) gideriminde etkin olan parametreler incelenmiş olup, aynı zamanda kinetik ve izoterm çalışmaları da yapılmıştır. En yüksek giderim miktarının belirlenmesi için gerekli biyosorbent miktarı hesaplanmıştır. Başlangıç $\mathrm{Pb}$ (II) konsantrasyonun artması ile biyosorpsiyon kapasitesi de artış göstermiştir. Yine artan sıcaklıkla da biyosorpsiyon kapasitesinin artmış olması olayın endotermik karakterde olduğunu göstermiştir. Kinetik veriler yalancı birinci derece modeline; izoterm verileri ise Langmuir izotermi modeline uygun gerçekleşmiştir. Bu çalışma herhangi bir ticari değeri olmayan zirai bir atık olarak kullanılan biyosorbentin $\mathrm{Pb}$ (II) gidermede belli bir potansiyele sahip olabileceğini ortaya koymuştur. Ayrıca farklı kirleticilerinde giderilmesinde alternatif bir kaynak olabileceğini ve böyle bir prosesle istenen kirlilik etmeninin geri kazanılabileceğini ifade etmekte mümkündür.

\section{Kaynakça}

Ahluwalia, S. S., \& Goyal, D. (2007). Microbial and plant derived biomass for removal of heavy metals from wastewater. Bioresource technology, 98(12), 2243-2257. doi: 10.1016/j.biortech.2005.12.006

Arslanoğlu, H., \& Tümen, F. (2015). Sitrik Asitle Modifiye Edilmiş Şeker Pancarı Küspesi ile Sulu Çözeltilerden $\mathrm{Pb}$ (II) ve Cd (II) Giderilmesi. Fırat Üniversitesi Mühendislik Bilimleri Dergisi, 27(1), 85-99.

Basu, M., Guha, A. K., \& Ray, L. (2017). Adsorption of lead on cucumber peel. Journal of Cleaner Production, 151, 603-615. doi: 10.1016/j.jclepro.2017.03.028

Bhattacharjee, C., Dutta, S., \& Saxena, V. K. (2020). A review on biosorptive removal of dyes and heavy metals from wastewater using watermelon rind as biosorbent. Environmental Advances, 2, 100007. doi: 0.1016/j.envadv.2020.100007

Chen, B., \& Chen, Z. (2009). Sorption of naphthalene and 1-naphthol by biochars of orange peels with different pyrolytic temperatures. Chemosphere, 76(1), 127-133. doi:10.1016/j.chemosphere.2.2009.02.004

Cruz, C. C., Da Costa, A. C. A., Henriques, C. A., \& Luna, A. S. (2004). Kinetic modeling and equilibrium studies during cadmium biosorption by dead Sargassum sp. biomass. Bioresource technology, 91(3), 249-257. doi: 10.1016/S0960-8524(03)00194-9

Demirbas, E., Kobya, M., Senturk, E., \& Ozkan, T. (2004). Adsorption kinetics for the removal of chromium (VI) from aqueous solutions on the activated carbons prepared from agricultural wastes. Water $\mathrm{Sa}, 30(4), 533-539$.

Demirbaş, E. (2003). Adsorption of cobalt (II) ions from aqueous solution onto activated carbon prepared from hazelnut shells. Adsorption Science \& Technology, 21(10), 951-963. doi: $10.1260 / 02636170360744380$

Freundlich, H. M. F. (1906). Over the adsorption in solution. Journel of Physical Chemistry, 57(385471), 1100-1107.

Göksungur, Y., Üren, S., \& Güvenç, U. (2005). Biosorption of cadmium and lead ions by ethanol treated waste baker's yeast biomass. Bioresource technology, 96 (1), 103-109. doi:10.1016/j.biortech.2003.04.002

Gundogdu, A., Ozdes, D., Duran, C., Bulut, V. N., Soylak, M., \& Senturk, H. B. (2009). Biosorption of $\mathrm{Pb}$ (II) ions from aqueous solution by pine bark (Pinus brutia Ten.). Chemical Engineering Journal, 153(1-3), 62-69. doi:10.1016/j.cej.2009.06.017 
Gupta, V. K., Rastogi, A., \& Nayak, A. (2010). Biosorption of nickel onto treated alga (Oedogonium hatei): application of isotherm and kinetic models. Journal of colloid and interface science, 342(2), 533-539. doi:10.1016/j.jcis.2009.10.074

Güneş, S. (2018). Artık materyal kullanılarak adsorpsiyon yöntemi ile atıksulardan kurşun giderimi. Pamukkale Üniversitesi, Fen Bilimleri Enstitüsü, Yüksek Lisans Tezi, Denizli.

Hall, K. R., Eagleton, L. C., Acrivos, A., \& Vermeulen, T. (1966). Pore-and solid-diffusion kinetics in fixed-bed adsorption under constant-pattern conditions. Industrial \& Engineering Chemistry Fundamentals, 5(2), 212-223. doi:10.1021/i160018a011

Hanif, M. A., Nadeem, R., Bhatti, H. N., Ahmad, N. R., \& Ansari, T. M. (2007). Ni (II) biosorption by Cassia fistula (Golden Shower) biomass. Journal of Hazardous Materials, 139(2), 345-355. doi: 10.1016/j.jhazmat.2006.06.040

Ho, Y. S., \& McKay, G. (1999). Pseudo-second order model for sorption processes. Process biochemistry, 34(5), 451-465. doi: 10.1016/S0032-9592(98)00112-5

Jaishankar, M., Tseten, T., Anbalagan, N., Mathew, B. B., \& Beeregowda, K. N. (2014). Toxicity, mechanism and health effects of some heavy metals. Interdisciplinary toxicology, 7(2), 60-72. doi: 10.2478/intox-2014-0009

Kavc1, E. (2021). Direct Red BWS tekstil boyas1 adsorpsiyonunun Taguchi L9 (34) ortogonal deney tasarımı ile araştırılması. Niğde Ömer Halisdemir Üniversitesi Mühendislik Bilimleri Dergisi, 10(1), 358-363.

Kavitha, D., \& Namasivayam, C. (2007). Experimental and kinetic studies on methylene blue adsorption by coir pith carbon. Bioresource technology, 98(1), 14-21. doi: 10.1016/j.biortech.2005.12.008

Kelly-Vargas, K., Cerro-Lopez, M., Reyna-Tellez, S., Bandala, E. R., \& Sanchez-Salas, J. L. (2012). Biosorption of heavy metals in polluted water, using different waste fruit cortex. Physics and Chemistry of the Earth, Parts A/B/C, 37, 26-29. doi: 10.1016/j.pce.2011.03.006

Lagergren, S. K. (1898). About the theory of so-called adsorption of soluble substances. Sven. Vetenskapsakad. Handingarl, 24, 1-39.

Langmuir, I. (1918). The adsorption of gases on plane surfaces of glass, mica and platinum. Journal of the American Chemical society, 40(9), 1361-1403. doi: 10.1021/ja02242a004

Morosanu, I., Teodosiu, C., Paduraru, C., Ibanescu, D., \& Tofan, L. (2017). Biosorption of lead ions from aqueous effluents by rapeseed biomass. New biotechnology, 39, 110-124. doi: 10.1016/j.nbt.2016.08.002

Öztürk, M., Yıldız, S., \& Aslan, Ş. (2020). Nikel (II) İyonlarının Atık Çay’a Biyosorpsiyonu: Denge, Kinetik ve Termodinamik Çalışmaları. Mühendislik Bilimleri ve Tasarım Dergisi, 8(4), 985998. doi: 10.21923/jesd.742918

Reddad, Z., Gérente, C., Andrès, Y., Ralet, M. C., Thibault, J. F., \& Le Cloirec, P. (2002). Ni (II) and $\mathrm{Cu}$ (II) binding properties of native and modified sugar beet pulp. Carbohydrate polymers, 49(1), 23-31. doi:10.1016/S0144-8617(01)00301-0

Robinson, T., Chandran, B., \& Nigam, P. (2002). Effect of pretreatments of three waste residues, wheat straw, corncobs and barley husks on dye adsorption. Bioresource technology, 85(2), 119-124. doi:10.1016/S0960-8524(02)00099-8

Şener, A., \& Ünal, M. Ü. (2008, May1s). Gıda sanayii atıklarının biyoteknolojik yöntemlerle değerlendirilmesi. Türkiye 10. G1da Kongresi, Erzurum.

Taşar, Ş., Kaya, F., \& Özer, A. (2014). Biosorption of lead (II) ions from aqueous solution by peanut shells: equilibrium, thermodynamic and kinetic studies. Journal of Environmental Chemical Engineering, 2(2), 1018-1026. doi: 10.1016/j.jece.2014.03.015

Vijayaraghavan, K., Palanivelu, K., \& Velan, M. (2006). Biosorption of copper (II) and cobalt (II) from aqueous solutions by crab shell particles. Bioresource technology, 97(12), 1411-1419. doi: 10.1016/j.biortech.2005.07.001

Wan, S., Ma, Z., Xue, Y., Ma, M., Xu, S., Qian, L., \& Zhang, Q. (2014). Sorption of lead (II), cadmium (II), and copper (II) ions from aqueous solutions using tea waste. Journal of Industrial and Engineering Chemistry Research, 53(9), 3629-3635. doi: 10.1021/ie402510s

Weber Jr, W. J., \& Morris, J. C. (1963). Kinetics of adsorption on carbon from solution. Journal of the sanitary engineering division, 89(2), 31-59. doi: 10.1061/JSEDAI.0000430

Weber, W. J. (1972). Physiochemical processes for water quality control. 
Yağcı, S., Altan, A., Göğüş, F., \& Maskan, M. (2006, Mayıs). Gıda atıklarının alternatif kullanım alanlart. Türkiye 9. Gıda Kongresi, Bolu.

Yargıç, A. Ş., Şahin, R. Y., Özbay, N., \& Önal, E. (2015). Assessment of toxic copper (II) biosorption from aqueous solution by chemically-treated tomato waste.Journal of Cleaner Production, 88,152-159. 